\title{
A Research on the Accounting Skills Teaching in Higher Vocational Colleges
}

\author{
Zhao Lei ${ }^{1, a}$ \\ ${ }^{1}$ School of Accounting and Auditing, Yunnan Technology and Business University, Kunming City, \\ Yunnan Province, 651701, China
}

Key words: Higher Vocational Education; accounting skills; skill teaching; teaching ways

\begin{abstract}
Strengthening the accounting major teaching of basic skills and professional skills in higher vocational colleges is not only the need of the development of Vocational Education, but also the need of the talent market and the positioning requirements of Higher Vocational Education. Based on the author's learning and teaching experience, this paper first discussed the necessity to strengthen the accounting skills teaching for Vocational School Students, then analyzed the problems of accounting skill teaching in Higher Vocational Colleges, finally put forward some feasible ways to strengthen the teaching of accounting professional skills.
\end{abstract}

\section{Introduction}

In June 2014, total 6 departments, including the Ministry of education and the Ministry of Finance, jointly issued Modern vocational education system construction plan 2014-2020, which pointed out the top level design of modern vocational education and the development direction of education system. This plan clearly pointed out that the goal of vocational education is to train high quality workers and technical talents. Higher Vocational Education is an important part of vocational education system, and its training goal is defined as the employment oriented, training the students applied talents, appropriate basic theory and strong ability to apply skills. For the employers, the new recruits are expected to have a basic understanding of the business processes, have strong operational ability and can get started quickly. Therefore, higher vocational colleges must attach importance to skill teaching and regarded it as an important part of teaching content, this is the need of the development of Vocational Education, and also the need of the talent market and the Positioning requirements of Higher Vocational Education. Specific to the accounting profession, vocational skills including basic skills and professional skills.

\section{The Necessity to Strength the Accounting Skill Teaching for Vocational School Students}

\subsection{The need of accounting professional training objectives}

The training objective of Accounting professional in Vocational Education is to train primary and intermediate skilled accounting talents, those students not only have good accounting professional ethics and basic knowledge of accounting position and higher accounting professional skills, but also are familiar with relevant laws and regulations. Furthermore, they can be engaged in a variety of accounting work quickly after graduation. Because of its special emphasis on professional skills requirements, the development of basic accounting skills teaching is not only the objective needs of professional teaching, but also the social needs of adapt to the current rapid economic development.

\subsection{The need to enhance the ability of students' employment post}

The essence of vocational education is employment education. At present, in most of the industry, we always hope the medium occupation schools to cultivate students with strong ability of post employment, which is also the strengths of the applied talent. Employers always wish the employed staff can be directly engaged in the work without spending training cost. The fundamental purpose of basic accounting skills teaching is to combine the theoretical knowledge with the practical skills, guide students to find problems, analyze problems and solve problems through the analysis and 
processing of the economic business of enterprises, and then improve students' ability to handle business and strengthen the occupation skills, finally enhance students' employment post.

\section{The Problems of Accounting Skill Teaching in Higher Vocational Colleges}

\subsection{Skill teaching is not comprehensive enough}

At present, the basic accounting skills teaching is mainly based on single project training, such as fill and check the original documents, prepare accounting entries, make accounting vouchers, registration books and prepare accounting statements etc, but there is little systematic comprehensive training in the teaching. Furthermore, most of the skills teaching are still using the traditional teaching mode, that is, theory first and practice later, on the other hand, the documents and books relate to the practice mostly derived from books or workbooks, so that the scope of these data is very limited, all of these are not conducive to students to master the whole accounting process.

\subsection{Actual operation in skill teaching process is not enough}

Many of the information used in the teaching of basic accounting skills is simulation or simulation business, and more information is coming from supporting materials. Students can only contact these information in the accounting simulation training room, hardly get the real information, moreover have chance to operate. In addition, restricted by conditions, vocational school students are very lack of external accounting skills training. Because of the special industry restrictions and the confidentiality of financial information, few higher vocational students can really conduct training in corporate finance departments in the base of the internship arrangements. Therefore, the current practice of teaching skills is not ideal.

\subsection{Skill teaching is lacking pertinence}

With the continuous development of social economy, the market demand for resources of talents has undergone great changes, and the standard of higher vocational talents is more focused on skilled personnel with skilled operation skills. Therefore, it requires schools to focus on skills teaching and train the students' practical ability, requires school must regard skills training as an important part of student training. However, some of the basic skills in the current skills training has not been given enough attention and strengthen, for example, filling and binding vouchers and accounting books. These reasons affect the adaptability of some students after graduation, and indirectly affect their employment post.

\subsection{Double qualified teachers need to be strengthened}

In recent years, the state pays more and more attention to the construction of double qualified teachers, select a large number of teachers to participate in the provincial and national key training, some teachers are also selected to attend full-time training enterprises, the overall level of skill teaching has been greatly improved. But it is undeniable that most of the finance and economics teachers in Higher Vocational Colleges go to school directly after graduation from the accounting major or similar major at present, many teachers are lack of professional practice experience, so practical teachers are few.

\subsection{Basic accounting training data is not enough}

Because most of the existing basic accounting textbooks are not accompanied by the original economic information, and mostly are coming from textbooks or related exercises, therefore, these textbooks are very limited, lack of practical characteristics. Those textbooks with original information is also not very comprehensive, involving a smaller scope, it is difficult for students to understand the economic business and account treatment through limited sources. Some teaching materials is just a mechanical backup from business information of a virtual enterprise in a certain period of time, lack of proper business analysis, processing and finishing process, which increases the students' learning difficulty. 


\section{Some Feasible Ways to Strengthen the Accounting Professional Skill Teaching}

\subsection{Pay enough attention to the skill teaching and explore the interest points of students' skill training}

The management and the teachers of Higher Vocational Colleges are very clear that the skill level of students is related to employment, and the employment situation is related to the reputation of the school and even survival. This ideological emphasis should be reflected in the specific behavior, such as special funds for the continued support of skill teaching resources, greater support for skill teaching in class scheduling, and provide more opportunities for exercise attachment and enterprise employment etc. The accounting profession is a boring subject, in which repetition of skills training can easily cause students' Burnout. Teachers should find the students' interest in the teaching of skills, and use the way that students are willing to accept.

\subsection{Establish an effective teaching guarantee system on software and hardware}

To establish an effective teaching guarantee system mainly includes the following aspects: First, curriculum. Basic skill is a kind of operation skill, students need to develop action skills, a better way is to be arranged in the first semester as a course, with many tests. Professional skills belong to intellectual skills, need theory teaching as the basis, can be arranged in each semester at the training semester, the teaching hours of professional skill training should be guaranteed in the course of adjusting the relevant courses, and its teaching hours should be guaranteed in the adjustment of the irrelevance curriculum. Second, courseware construction. The first batch of "12th Five-Year" occupation education has more than 4 thousand and 700 national planning materials list, in which there is only one basic accounting skills. Courseware is also the same case, there are few courseware for teaching skills. Skill teaching courseware is different from theory teaching courseware, it should be a collection of various types of documents accounts, animation video as a whole, be a multimedia courseware that can show the simulation accounting business process. The development of teaching courseware should follow the way of combining school and enterprise in order to improve the authenticity and practicability. Third, training room construction. The teaching and training of professional skills mainly rely on school training room. Due to the limitation of the site, many colleges and universities training room have no difference with common computer room. Regardless of the size of the area, the construction of the training room should be simulated as much as possible, include the environment simulation and the training props simulation, and must be completed. Small area training room can be arranged for small classes for separate training. Fourth, teachers construction. Ideal skill teacher team should be composed by school full-time teachers and enterprise teachers.

\subsection{Design reasonable skill teaching assessment method}

The basic skills can be used multiple assessment methods. After the end of the course, teachers should develop a basic skills assessment program during the school period, it can be once a semester or several times. Assessment of the basic skills do not need to take much time, it can be decentralized or gathered, which ensures that students can be continue training and skills are always in hand. Because professional skills assessment is involving a large number of documents account and assessment points are scattered, teachers can choose the examination software from the accounting teaching software. School can also use the form of competition in assessment, if it is difficult to held a comprehensive skills competition, the school can conduct a small single skills competition, because competitive environment is also conducive to stimulate students' initiative. The evaluation results can be linked properly to all kinds of students appraised, scholarship and employment recommendation.

\subsection{In the internet plus era, pay more attention to the training of comprehensive skills and occupation moral}

In the Internet plus era, is it necessary for the training of accounting skills, especially basic skills? From the diversity of the accounting environment, the answer is yes. And in Internet plus era the 
scope of accounting skills is widened, which puts forward higher requirements to the teaching of accounting skills. We should pay more attention to the study of the boundary subjects with accounting, should pay more attention to the use of the computer network finance, and should pay more attention to the cultivation of accounting professional ethics.

\section{Summary}

With the continuous reform of accounting Vocational Education, skill teaching reform has become the key component. The vocational skills competition can effectively promote the level of practice teaching in school, become an important way to evaluate the quality of vocational education teaching skills, and it also promotes the healthy development of Vocational Education. In order to further improve the students' application ability and comprehensive quality, we should gradually change the current teaching mode, improve the training conditions, strengthen the teachers construction, and make the students' learning close to the job, improve students' practical ability, promote the development of accounting vocational education from scale development to quality development, and contribute to a better tomorrow for Vocational Education.

\section{References}

[1] Lu Chunfen. On the influence of accounting skills competition on Higher Vocational Accounting Teaching [J]. modern economic information, 2016,(04):421-422.

[2] $\mathrm{Lu} \mathrm{Yu}$. The optimization of accounting skill teaching and promote the financial strategy in the [J]. era, 2015, (23): 143-144.

[3] Zhang Hanmei. Analysis of class teaching of Accounting Specialty in secondary vocational schools [J]. financial sector (Academic Edition), 2015, (08): 231-232.

[4] Huang Zhu Mei. Lead the secondary vocational accounting teaching reform of small and medium sized enterprises [J]. management and technology skills competition (a), 2014 (09): 240-241.

[5] Xu Wei. Accounting skills competition effect on five year Vocational Accounting Teaching of [J]. technology and market, 2014, (03): 163-164.

[6] Liu Juan. On the teaching experience of accounting skills in vocational schools [J]. Shang, 2013, (10): 78+68.

[7] Yang Xiaoyu. The influence of accounting skills competition on Secondary Vocational Accounting Teaching and Countermeasures [J]. Journal of Jilin Institute of Education (early), 2013, (01): 97-98. 